\title{
Stakeholder's Participation in Technology Assessment, Refinement and Validation
}

\author{
Anshu* and Seema Rani \\ Department of Extension Education and Communication Management, CCS Haryana \\ Agricultural University, Hisar-125004 (Haryana), India \\ *Corresponding author
}

\section{A B S T R A C T}

\begin{tabular}{|l|}
\hline Keyw or d s \\
ATMA, \\
Technology, \\
Participation, \\
Stakeholders \\
\hline Article Info \\
\hline $\begin{array}{l}\text { Accepted: } \\
\text { 07 May } 2019 \\
\text { Available Online: } \\
\text { 10 June } 2019\end{array}$ \\
\hline
\end{tabular}

\section{Introduction}

Over the last several decades, considerable effort has been made throughout the world to provide women farmers and women on the farm with efficient, effective, and appropriate technology, training, and information still only 5 percent of the agricultural extension resources are directed towards women. The Agricultural Technology Management Agency (ATMA) is a new mechanism of Indian government at district level, to increase relevance, accessibility, and efficiency of knowledge sharing among various farmers and stakeholders. Technology is the collection of techniques, skills, methods, and processes used in the production of goods or services or in the accomplishment of objectives, such as scientific investigation. The activities of ATMA technology assessment, refinement, and transfer, aiming to bridge the gap between the technologies developed at research stations and its adoption at field level. The technology validation/ dissemination was made demand-driven, market-led and farmer accountable, through bottom-up, participatory planning procedures. Keeping the context the study will be conducted with the following objectives: 
1. Participation of different stakeholders at different stages of technology assessment, refinement and validation

2. Extent of awareness about the technology generation/refinement/validation activities.

\section{Materials and Methods}

To determine the participation, awareness about technology assessment, refinement, 20 stakeholders of ATMA were selected randomly from Hisar division of Haryana. The data were collected personally with the help of questionnaire. The data were tabulated and analyzed to draw the meaningful interferences.

\section{Results and Discussion}

\section{Socio-economic profile of the stakeholders} under ATMA

Majority (55.00\%) of stakeholders were block agriculture officers followed by agriculture development officer $(25.00 \%)$, agriculture technology manger $(15.00 \%)$ and block technology manager $(5.00 \%)$. Majority $(75.00 \%)$ belonged to general caste followed by backward caste $(20.00 \%)$ and SC/ST caste $(5.00 \%)$. All the stakeholders were working in Agriculture \& Farmers Welfare Department. Majority of stakeholders had Masters Degree (40.00\%) followed by Master of Business Administration (30.00\%), Graduation
(25.00\%) and Doctor of Philosophy (5.00\%). Experience is an important parameter to specify competence and output of an individual. A good majority of stakeholders had 10-20 years of experience and 35.00 per cent of stakeholders had less than 10 years of experience and involvement with ATMAranged from 5 to 10 years $(50.00 \%)$.

Table 1 reveals that the extent participation of stakeholders in various steps of technology generation varies owing to different reasons. The participation was found to be highest in identification of research issue was ranked I followed by implementation of the FPR trial ranked II, designing the FPR trial with indication treatments was ranked III as well as prioritizing the issues, recommendation of the findings was ranked IV, monitoring and evaluation of the trials ranked $\mathrm{V}$ and planning the FPR trial including selection of farmer ranked VI.

The data further reveals that in extension system, identification of research issue was ranked I followed by prioritizing the issues ranked II, planning the FPR trial including selection of farmer ranked III, recommendation of the findings ranked IV, implementation of the FPR trial ranked V, monitoring and evaluation of the trials ranked VI and designing the FPR trial with indication treatments VII.

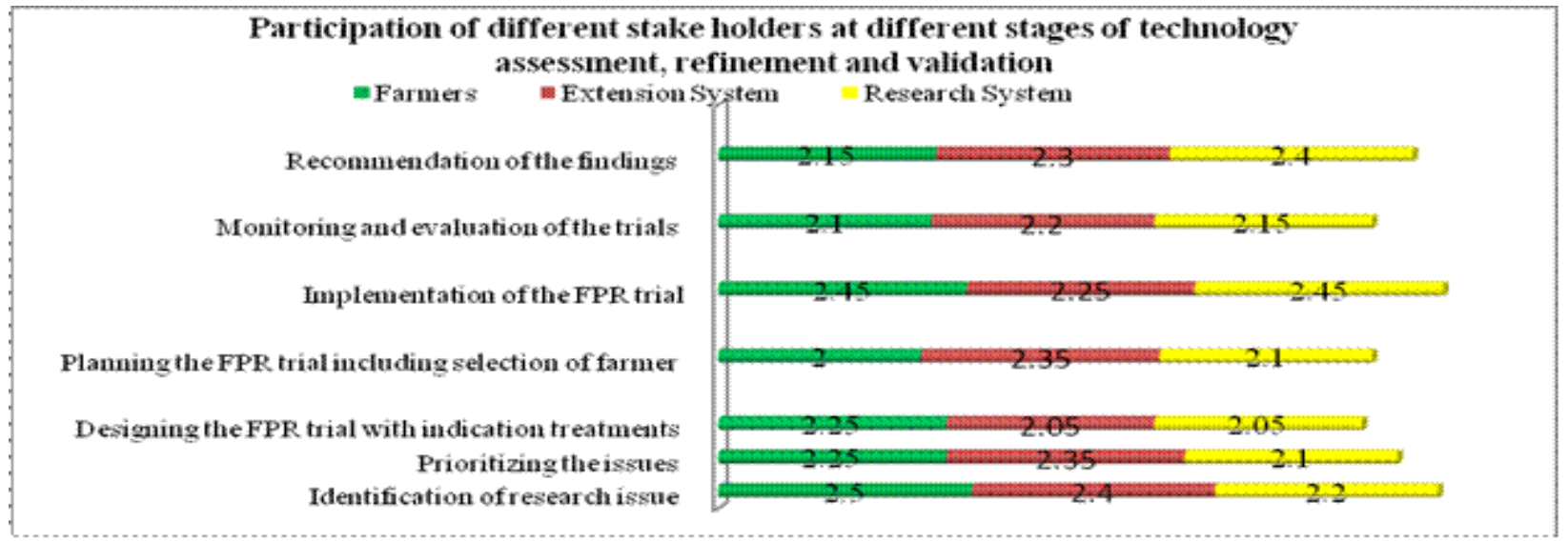


The data reported in Table 1 also brings to light that in case of research system, implementation of the FPR trial ranked I followed by recommendation of the findings ranked II, identification of research issue ranked III, monitoring and evaluation of the trials ranked IV, planning the FPR trial including selection of farmer ranked $\mathrm{V}$ as well as prioritizing the issues and designing the FPR trial with indication treatments ranked VI. The results indicate that cereals had highest mean score (2.7) in regards to awareness of stakeholders about the technology generation/ refinement/ validation activities followed by pest and diseases management (2.5), water management (2.5), integrated weed management (2.45), postharvest and value addition (2.4), nutrient management (2.35), pulses (2.3), agri implement (2.3), oilseeds (2.25), soil management (2.25), vermicomposting (2.05), dairy (1.9), mushroom (1.85), fruits (1.75), goatery (1.7), flowers (1.7), spices (1.65), poultry (1.65), vegetable (1.6), pisciculture (1.45) and apiary (1.4) (Table 2).

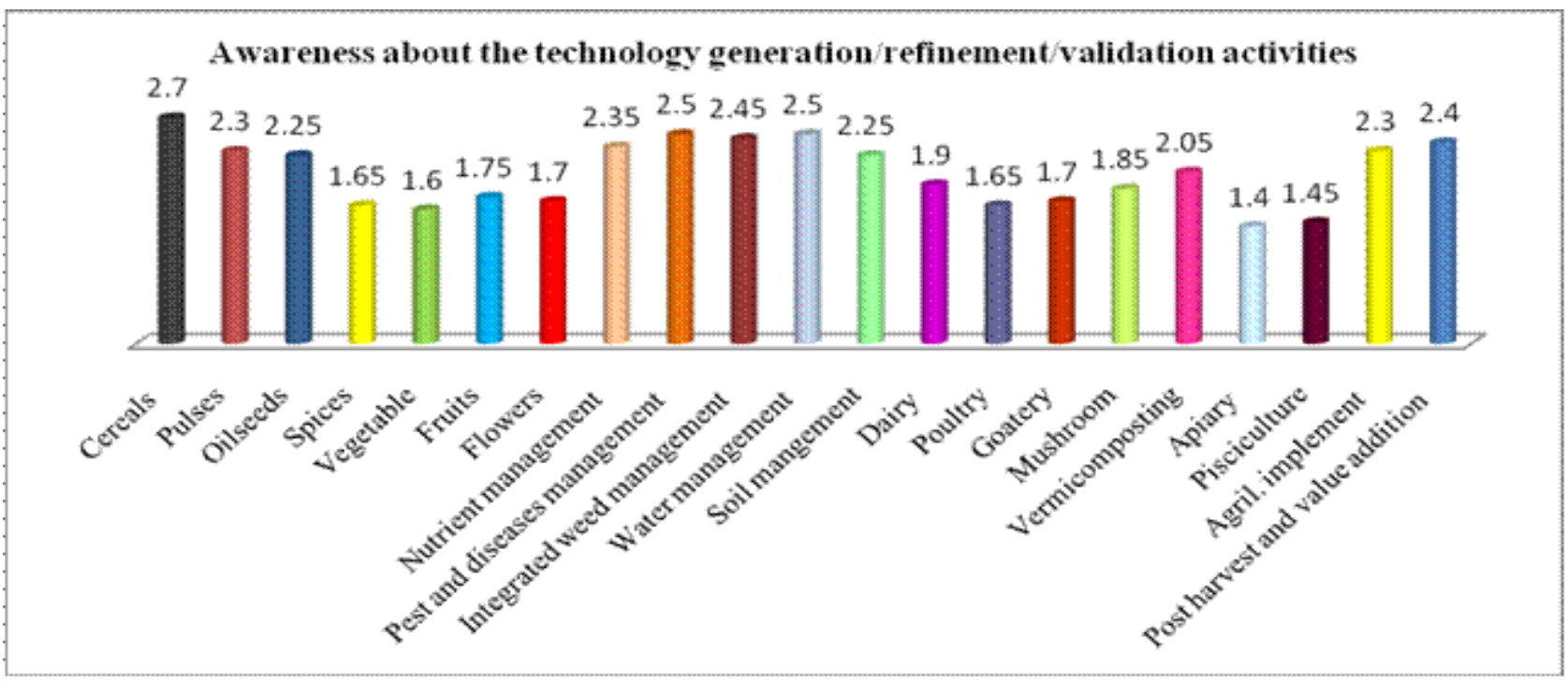

Table 3 reveals that extent of awareness about the technology generation/refinement/ validation activities was found to be medium $(65.00 \%)$ followed by high $(20.00 \%)$ and low $(15.00 \%)$. The data pertaining in Table 4 revealed that stakeholders agreed that that technology in ATMA project is generally transferred at the farmer doorstep which had highest mean score (4.6) followed by need based (4.4), affordable for the farmers (4.35), timely (4.3), acceptable to farming community (4.25), understandable language (4.2), easy to operate (4.2), compatible with existing farming system (4.15), high rate of productivity (4.15) and designed for improving overall income of the farmer (4.05).
Data related to participation of different stake holders at different stages of technology assessment, refinement and validation reveal that identification of research issue was ranked $I$ in the role played by farmers followed by implementation of the FPR trial ranked. The data further reveals that in extension system, identification of research issue was ranked $\mathrm{I}$ in the extension system followed by prioritizing the. The data also brings to light that in case of research system, implementation of the FPR trial ranked I in research system followed by recommendation of the. The participation was found to be highest in identification of research issue and implementation of the FPR trial. 
Table.1 Participation of different stakeholders at different stages of technology assessment, refinement and validation

$$
\mathrm{N}=20
$$

\begin{tabular}{|c|c|c|c|c|c|c|c|}
\hline \multirow{3}{*}{$\begin{array}{l}\text { Sr. } \\
\text { No }\end{array}$} & \multirow[t]{3}{*}{ Stages } & \multicolumn{6}{|c|}{ Extent of participation } \\
\hline & & \multicolumn{2}{|c|}{ Farmers } & \multicolumn{2}{|c|}{$\begin{array}{l}\text { Extension } \\
\text { system }\end{array}$} & \multicolumn{2}{|c|}{$\begin{array}{l}\text { Research } \\
\text { system }\end{array}$} \\
\hline & & MS & Rank & MS & Rank & MS & Rank \\
\hline 1 & Identification of research issue & 2.5 & I & 2.4 & I & 2.2 & III \\
\hline 2 & Prioritizing the issues & 2.25 & III & 2.35 & II & 2.1 & $\mathrm{~V}$ \\
\hline 3 & Designing the FPR trial with indication treatments & 2.25 & III & 2.05 & VII & 2.05 & VI \\
\hline 4 & Planning the FPR trial including selection of farmer & 2 & VI & 2.35 & III & 2.1 & $\mathrm{~V}$ \\
\hline 5 & Implementation of the FPR trial & 2.45 & II & 2.25 & V & 2.45 & I \\
\hline 6 & Monitoring and evaluation of the trials & 2.1 & $\mathrm{~V}$ & 2.2 & VI & 2.15 & IV \\
\hline 7 & Recommendation of the findings & 2.15 & IV & 2.3 & IV & 2.4 & II \\
\hline
\end{tabular}

Maximum Obtainable Score 3

Table.2 Awareness about the technology generation/refinement/validation activities undertaken by research system in the following areas under ATMAN=20

\begin{tabular}{|l|l|l|l|}
\hline $\begin{array}{l}\text { Sr. } \\
\text { no }\end{array}$ & Commodity / Crop & Mean score & Rank \\
\hline $\mathbf{1}$ & Cereals & 2.7 & I \\
\hline $\mathbf{2}$ & Pulses & 2.3 & VI \\
\hline $\mathbf{3}$ & Oilseeds & 2.25 & VII \\
\hline $\mathbf{4}$ & Spices & 1.65 & XIII \\
\hline $\mathbf{5}$ & Vegetable & 1.6 & XV \\
\hline $\mathbf{6}$ & Fruits & 1.75 & XI \\
\hline $\mathbf{7}$ & Flowers & 1.7 & XII \\
\hline $\mathbf{8}$ & Integrated nutrient management & 2.35 & V \\
\hline $\mathbf{9}$ & Integrated pest and diseases management & 2.5 & II \\
\hline $\mathbf{1 0}$ & Integrated weed management & 2.45 & III \\
\hline $\mathbf{1 1}$ & Water management & 2.5 & II \\
\hline $\mathbf{1 2}$ & Soil management & 2.25 & VII \\
\hline $\mathbf{1 3}$ & Dairy & 1.9 & IX \\
\hline $\mathbf{1 4}$ & Poultry & 1.65 & XIV \\
\hline $\mathbf{1 5}$ & Goatery & 1.7 & XII \\
\hline $\mathbf{1 6}$ & Mushroom & 1.85 & X \\
\hline $\mathbf{1 7}$ & Vermicompost & 2.05 & VIII \\
\hline $\mathbf{1 8}$ & Apiary & 1.4 & XVII \\
\hline $\mathbf{1 9}$ & Pisciculture & 1.45 & XVI \\
\hline $\mathbf{2 0}$ & Agril. implement & 2.3 & VI \\
\hline $\mathbf{2 1}$ & Post harvest and value addition & 2.4 & IV \\
\hline
\end{tabular}

Maximum Obtainable Score 3 
Table.3 Extent of awareness about the technology generation/refinement/validation activities undertaken by research system in the following areas under ATMA

\begin{tabular}{|l|l|l|}
\hline Level & Score & Frequency (\%) \\
\hline High & $>48.81$ & $4(20.00)$ \\
\hline Medium & $48.81-36.59$ & $13(65.00)$ \\
\hline Low & $<36.59$ & $3(15.00)$ \\
\hline
\end{tabular}

Table.4 Perception of stakeholders about the characteristics of technology transferred to farmer

\begin{tabular}{|l|l|c|c|}
\hline Sr.No & Technology & Mean score & Rank \\
\hline $\mathbf{1}$ & Need based & 4.4 & II \\
\hline $\mathbf{2}$ & Timely & 4.3 & IV \\
\hline $\mathbf{3}$ & Understandable language & 4.2 & VI \\
\hline $\mathbf{4}$ & At the farmer doorstep & 4.6 & I \\
\hline $\mathbf{5}$ & Compatible with existing farming system & 4.15 & VII \\
\hline $\mathbf{6}$ & Affordable for the farmers & 4.35 & III \\
\hline $\mathbf{7}$ & High rate of productivity & 4.15 & VII \\
\hline $\mathbf{8}$ & Easy to operate & 4.2 & VI \\
\hline $\mathbf{9}$ & Acceptable/useful to farming community & 4.25 & V \\
\hline $\mathbf{1 0}$ & Designed for improving overall income of the & 4.05 & VIII \\
& farmer & & \\
\hline
\end{tabular}

Maximum Obtainable Score 5

The results indicate that cereals had highest mean score in regards to awareness of stakeholders about the technology generation/ refinement/ validation activities followed by pest and diseases management. The data revealed that stakeholders agreed that that technology in ATMA project is generally transferred at the farmer doorstep which had highest mean score followed by need based, affordable for the farmers.

That data shows that majority of stakeholders had medium level of awareness about the technology generation/ refinement/ validation activities and to increase the awareness level on the job training should be provided. Technologies plays important role in everyday life of persons and efforts of ATMA in technology assessment, refinement and validation are commendable.

\section{References}

Directorate of Agriculture, ATMA Schemes. https://dag.gujarat.gov.in/atmaschemes.html

Liddell, Henry George; Scott, Robert (1980). A Greek-English Lexicon (Abridged Edition). United Kingdom: Oxford University Press.

\section{How to cite this article:}

Anshu and Seema Rani. 2019. Stakeholder's Participation in Technology Assessment, Refinement and Validation. Int.J.Curr.Microbiol.App.Sci. 8(06): 705-709. doi: https://doi.org/10.20546/ijcmas.2019.806.082 